\title{
Integrating Wildlife into the Managed Forest
}

\author{
by
}

\author{
Hal Salwasser ${ }^{1}$
}

\begin{abstract}
Integrating wildlife habitat concerns into multipleuse forest management requires four things: 1) the right attitude, 2) a process for systematic resource coordination, 3 ) models that relate forest conditions to wildlife outputs, and 4) the effective use of monitoring to support an adaptive management strategy. These four things reflect that resource managers must first want to make forestry-wildlife coordination work, that they need a mechanism for doing it, that they need habitat criteria for meeting wildlife goals, and that we only know enough at this time to get pointed in the right direction.

Comprehensive goals for timber and wildlife are set early in successful forestry-wildlife integration. The goals provide for maintaining habitat and wildlife diversity while simultaneously producing consumable surpluses of timber and game in relation to demands for those products. Comprehensive inventories and vegetation growth and yield models are used to analyze the current management situation and show the need for actions to meet goals. The wildlife yield models are species-habitat relationships functions that relate habitat conditions to wild life outputs by species. The management plan developed constitutes a coordinated set of resource objectives and the schedule of practices that will achieve them in an efficient way. Monitoring the effects of the practices is used to learn whether assumptions and models used in planning need to be revised, and whether the course of management needs to be adjusted to meet the goals.
\end{abstract}

Key words: Forest management, Wildlife management, integration, Wildlife habitat, Multiple use planning.

\section{Introduction}

Theories about managing a forest for wood and wildlife can range from simple-minded, often inaccurate notions like, "Good forest management is good wildlife management," to complicated, unworkable perceptions like considering quantitatively and specifically the time and space dynamics of all 300 vertebrate species in a forest. Any forest is a complicated ecosystem of thousands of interrelated living and nonliving

1National Wildlife Ecologist, USDA Forest Service, 3825 E. Mulberry St., Fort Collins, Colorado, USA parts. But we can't possibly understand all of the relationships. Furthermore, not all of them are equally important.

The central problem in integrating wildlife and timber goals in managed forests is to sift from all the natural complexity those few things that are useful, if not essential, in controlling forest dynamics to meet the specific mix of goals. Automatically this means to simplify reality to the point where we can communicate what it is we want to accomplish, and apply treatments to effect that end.

In their recent bestseller, In Search of Excellence, Peters and Waterman (1982) stress the importance of chunking complex things into a series of doable tasks. The chunks I will address here are 1) the management goals, 2) the area of control, 3) the time stream of benefit flows, 4) the elements of control, 5) some planning tools, and 6) some management principles. Together they constitute much of the complexity of integrating timber and wildlife. Of course, each of them is complex enough in its own right to warrant a separate paper. My purpose here, however, is to cover each briefly and stress how they must hang together to achieve true timber-wildlife integration.

\section{The Goals of Timber-wildlife Integration}

There are two major purposes for which forests can be managed with wildlife in mind: diversity (often called species richness management), and featured species production (also called emphasis species management) (Thomas 1979). The simplest approach to timber-wildlife integration is to focus on only one of these purposes. The more difficult task is to blend both with the overall purposes of forest management.

In management for diversity, the forester emphasizes the perpetuation of all cover types, successional stages, and instand features (e.g., snags and fallen trees), collectively the habitat elements of diversity. The sizes, shapes, relative proportions, and locations of these elements are designed to provide for the full richness of plant communities and wildlife species in an area (Siderits and Radtke 1977). In principle, all species are provided for equally: i.e., none are purposefully excluded from the forest.

In management for featured species, the forester emphasizes the perpetuation of those cover types, successional stages, and in-stand features that promote production of the desired species (Holbrook 1974). The featured species might be a plant (e.g. Douglas-fir), a game animal (e.g., elk), or a combination of specific plants and animals. The result is that some species are favored over others. In the extreme some species could be excluded from large areas of land that are being managed for the selected species. 
Full integration of wildlife and timber in a managed forest requires specific, quantitative goals for wildlife products. These goals must be translated into habitat conditions that can be effected by silvicultural and harvesting practices. At the fullest, integration combines diversity and featured species with wood fibre production. Maintaining viable populations of all native and desired nonnative vertebrates sets the diversity, or land ethic, foundation to multiple-benefit forest conservation (Salwasser 1983; Salwasser et al., 1984b). It entails the perpetuation of sufficient kinds, amounts, and locations of all the habitats needed for survival and reproductive success of all species in an area. Experience in US national forests shows that maintaining the necessary diversity requires about 5 to $10 \%$ of the commercial forest land base. The remaining 90 to $95 \%$ is available for all other uses.

On the forest lands available after the diversity needs are met the mix of uses should reflect four concerns: 1) socioeconomic needs of the landowner and local and regional users, 2) land and habitat capability to produce different resources, 3) logistic and economic feasibility of proposed land uses, and 4) compatibility of wildlife goals with other resources and land uses. Common sense dictates that the wildlife species to be featured on an area meet these criteria (Salwasser and Tappeiner 1981).

To gain efficiency in meeting the multiple-resource goals for an area, habitat conditions that enhance productivity should be favored, and conditions that reduce productivity should be suppressed. For example, insect-eating birds may help reduce forest pest problems, and some small mammals disperse micorrhizae and the seeds of nitrogen-fixing plants. Favoring them by leaving snag and fallen tree habitats could enhance wood fibre production (Maser and Trappe 1984). Other species, such as gophers, mountain beavers, and "nonfeatured" plants can be managed to minimize negative effects on the featured resources.

To summarize, timber-wildlife integration begins with quantitative and specific goals. Minimum habitat standards to maintain species diversity is the basic goal. Beyond diversity, goals emphasize habitat conditions to favor featured plants and wildlife. Such a "diversity-plus-resource-production" goal blends a land ethic with efficient management for sustained yields of the multiple-benefits a managed forest can provide.

\section{The Area of Control for Integrated Timber-Wildlife Management}

The issues of diversity and sustained yield resource production must be viewed differently at at least four geographic levels: 1) the province, or region, 2) the forest, management district, or tree farm, 3) the watershed, seasonal range, or diversity unit, and 4) the site, stand, or habitat patch. At the province or region level the issue is major, long-term land use allocations. How much land to allocate to and where to put parks, refuges, agricultural land, and commercial forests are examples. These decisions exert a "higher level control" on diversity and resource production potentials. Maintenance of full faunal diversity is strongly emphasized through endangered species legislation and the major land use allocations at this level.

At the management district (forest or tree farm) level, the issue is still land use allocation, but the time frame is shorter and the geographic specificity is more flexible. Each district must decide how much land to allocate, and where to put the cover types and successional stages to help meet the goals of the province or region. Only in the US national forests (to my knowledge) do laws and regulations mandate the perpetuation of full faunal diversity at this level.

At the watershed level the issue is the time and space dynamics of individual vegetation stands (read habitat patches) relative to the home range needs of large animals, logging transportion costs, environmental standards (e.g., stream water quality), and sustained yields of resources. Common concerns are the richness of cover types and successional stages, their proportions in the watershed, and the geography of individual stands (i.e., size, shape, and location).

At the stand (habitat patch) level the issue is the time dynamics of the floristic and structural characteristics of each stand. Feeding and cover substrates (e.g., grass, shrub, understory tree layer, canopy trees, snags, and fallen trees) and the efficient production of wood fibre must be reconciled at this level.

\section{The Flows of Benefits}

There are three general patterns of benefit flows: 1) shortterm maximum production (a highly oscillating flow), 2) fluctuating flows within maximum and minimum bounds set to sustain local or regional economies and resource use industries, and 3) long-term even-flows at optimum mixes of sustainable yields. Short-term maximum production heavily discounts the future value of resources. It is difficult to argue that it is a conservation policy. Exploitation better describes the strategy.

Both fluctuating flow and even-flow are sustained yield conservation strategies. The difference is largely in the degree to which short-term market forces are allowed to influence investments and harvests. I do not wish to argue the merits or demerits of either, rather I want to make the point that both of these strategies require the concept of area control on the mix of cover types and successional stages. The crucial point for timber-wildlife integration is how big the area should be.

An area of size range 5 to 500 ha is usually too small to control the sustained yield of timber or wildlife habitat. On the other hand, the largest animals have home ranges on the scale of 500 to $10000 \mathrm{ha}$, making areas of 100000 to 1000000 ha quite large to control for sustained yields of habitat within a species' home range. It is becoming common practice in the US national forests to control for diversity and wildlife habitats on what are called management units or diversity units. These are areas of as small as 200 ha in the east to as large as 5000 ha in the west. Logistics of transportation, the featured wild life species, and the configuration of land ownership and watershed boundaries are among the criteria for deciding the unit for area control.

\section{The Elements of Control}

There are only four major habitat characteristics that must be controlled to effect timber-wildlife integration: 1) richness of the cover types and successional stages in the area of control, 2) proportions of the types and stages, 3) geography of the individual stands (patches), and 4) floristic and structural characteristics of the individual stands.

Physical parameters such as soils, climate, elevation, slope and aspect control the potential richness of cover types. Managers can partially influence cover type richness through enhancing or reducing the kinds of natural communities present. They have a much greater influence on the successional stages of the cover types present. Stages such as old growth can be eliminated, duration of stages such as grass-forb can be shortened, or the number of stages can be increased over the natural condition through timber harvest, regeneration, and stand tending.

The proportions of cover types and successional stages in the control area can be greatly influenced by management actions. Rotation lengths and the desired products, i.e., pulp versus sawtimber, hardwood chips versus veneer lumber, and turkeys versus bobwhite quail, will affect how much of an area needs to be in early or later successional stages. 
The geography of stands is also greatly influenced by management goals and actions. The size of each stand, its shape and location relative to other stands can determine whether all habitat needs are met within the normal home range area of a wildlife species. Large stands (1000 ha) on flat terrain can be all cover or all forage to an animal that needs a mix of both in a relatively small area (100 ha).

Much of the wildlife habitat value of an area of land is controlled through two factors: 1) proportion of cover types and stages, and 2) geography of the individual stands. They are in turn controlled by an area prescription that addresses issues like rotation lengths, and size and location of treatments.

The final element of control is what happens in the individual stand. The mix of plant species, the vertical structure of the stand (i.e., the number of distinct vegetative layers in the stand), and the abundance of in-stand features like snags and fallen trees determine the variety and quality of habitat substrates upon which the different species can find suitable foods or cover. These are in turn controlled by the stand prescription that addresses activities like the kind of harvest, site preparation stocking, release, juvenile spacing, and fertilization

The four major elements of control - richness, proportions, geography and stand characteristics - require attention in both the area and stand prescriptions.

\section{Planning Tools for Integrated Timber-Wildlife Management}

The most important planning tool for timber-wildlife integration is a systematic process for interdisciplinary resource coordination. The process evolving for the US national forests encompasses five major parts (local versions may distinguish more or fewer than five): 1) problem definition,2) management situation analysis, 3) management alternative formulation, 4) evaluation of the effects of alternatives, and 5) action, monitoring, and revision. As with all human endeavors the process is of little value if the participants do not share a commitment to resolve potential conflicts. Attitude is more important than process or technology in successful resource coordination.

Problem definition has three parts to it. First is delineation of a common project and analysis area. The area must be a contiguous unit of land that encompasses the home ranges of the largest wildlife species. This area will become the land unit for the area control issue described earlier. Watersheds in the 5000 to 10000 ha size range are usually adequate. The second step in problem definition is to identify the resource issues and opportunities that will be addressed. This is where all the natural complexity of forest ecosystems gets reduced to the meaningful set of goals that managers will strive for and the controls that they will manipulate to get there. The third step is to establish criteria against which alternative management courses can be evaluated. These evaluation criteria will be the rules that guide analysis. They might include legal requirements, specific resource goals, environmental effects and economic concerns.

Analysis of the management situation includes 1 ) collection and summarization of inventories pertinent to the issues, opportunities and evaluation criteria, and 2) analyses of current conditions, trends and potentials. An important point here is that in the coordination process, inventory and assessment of potentials are subservient to the identification of issues and specification of evaluation criteria. A major breakdown in timber-wildlife integration can often be traced to unclear or hidden issues and criteria for wildlife, or the failure of biologists to communicate them to foresters. Also, inventories conducted without specific focus on clearly defined problems run the risk of being inefficient and possibly irrelevant.
The major new technologies in assessing current conditions, trends, and potentials for wildlife resources rely on explicit models of species' relationships to different conditions of habitats (Thomas 1979 and many others). Under the general title "habitat-species relationships," these models include habitat classifications, coefficients that rate the relative value of the habitat classes to all species, models that rate areas of land for their capacity to support a given species, and simulation models to project future habitat conditions under alternative management courses (Nelson and Salwasser 1982). These tools allow quantitative estimates of species richness the habitat's capability to support indicator species, and of the cumulative effects of management alternatives on these species. The British Columbia Habitat Handbook program is a Canadian example of such a set of tools (Harcombe, 1984).

From assessments made in the analysis of the management situation the interdisciplinary team formulates alternatives that meet varying combinations of the environmental conditions and resource goals established during problem definition. In this step specific temporal and spatial environmental standards and resource objectives are tied to area and stand prescriptions for management actions. Activities are scheduled and outputs and costs determined for each alternative.

Prior to a decision the alternatives are evaluated relative to the criteria specified during problem definition. The degree to which standards and goals would be met, and the costs of meeting them are displayed for the decision maker and interested cooperators and publics.

When a decision is made actions are undertaken to move forest conditions to the states that meet resource goals. We know, a priori, that the assessments, based on inventories and assumptions that are less than perfect, will probably not accurately predict what will happen on the ground. Therefore, monitoring is used both to check on attainment of objectives and standards, and test the validity of assumptions made in planning. The more uncertain the expected outcome of a plan, and the more that is at stake in terms of resources or legal mandates, the more an investment in monitoring is warranted (Salwasser et al. 1983).

\section{Principles for Integrated Timber-Wildlife Management}

To summarize this paper I want to highlight five principles that are crucial to successfully integrating the management of timber and wildlife.

The first principle is that attitude is more important than laws, procedures, or technology in resource coordination. Jack Ward Thomas (this proceedings) addresses this point in detail. Wildlife goals must be explicit and well communicated early in the planning process. The bottom line is that people have to want to manage forests for wildlife and timber in the first place. There are always ways to subvert the laws and policies if folks have a mind to.

The second principle is that major land use allocation, as to parks, refuges, wilderness, and managed forests, is a societal commitment to resource integration at the large scale. Such allocations are designed to set general priorities for land uses on different areas. Timber-wildlife integration is a different beast on multiple-use forests than it is on commercial tree farms.

The third principle is that the management area prescription, by designating proportions of successional stages, sizes of vegetation treatments, and the geographic location of the treatments, is the major influence on wildlife diversity in a watershed. We call this landscape diversity (Salwasser et al. $1984 a)$. The area prescription must address not only timber concerns for scheduling and sustained yields, but also the 
home range habitat needs of the featured wildlife species

The fourth principle is that the stand prescription controls the vegetative substrates upon which different wildlife species can find food and cover resources. Dominant tree species, stocking rates, understory vegetation, the duration of distinct successional stages (i.e., grass-forb-seedling tree, shrubsapling tree, pole tree, small sawtimber, large sawtimber, and old growth), and the presence of in-stand habitat elements (e.g., snags and fallen trees) are all affected by the stand prescription (Salwasser et al. 1984a). They in turn affect wildlife species richness (which we call stand diversity), and the productive capacity of each stand for the featured plant and animal species.

The fifth principle is perhaps as important as the first. Monitoring is the key to adaptive resource management. Resource management must be responsive to new knowledge and adaptive to changing ecological and social conditions (Salwasser et al. 1983). Regardless of the elegance of inventories and planning models, our predictions of the results of planned treatments will always be less accurate than desired. In many cases they may be way off. The only way to learn from our management "experiments," and changing ecological conditions and social goals is to monitor both the forests and the forest users. Research is vital, but it cannot answer all of management's questions. A commitment to monitoring is crucial to the continued success of integrated, multiple-use forest management.

\section{References}

Harcombe, A. 1984. Wildlife habitat handbook project. BC Min. of Forests Min. of Environment. MIE Tech. Rep. 8. 237 p.
Holbrook, H.L. 1974. A system for wild life habitat management on southern national forests. Wildl. Soc. Bull. 2: 119-123.

Maser, C and J.M. Trappe (eds.) 1984. The seen and unseen world of the fallen tree. USDA Forest Serv., Pac. Northwest Forest and Range Exp. Sta., Portland, Oreg., in coop. with USDI, Bur. Land. Manage. Gen. Tech. Rep. PNW-164.

Nelson, R.D. and H. Salwasser. 1982. The Forest Service wildlife and fish habitat relationships program. Trans. North Am. Wildl. and Nat. Resour. Conf. 47: 174-183.

Peters, T.J. and R.H. Waterman, Jr. 1982. In Search of Excellence. Harper and Row, New York, $360 p$

Salwasser, H. and J.C. Tappeiner II. 1981. An ecosystem approach to integrated timber and wildlife habitat management. Trans. North Am. Wildl. and Nat. Resour. Conf. 46: 473-487.

Salwasser, H. 1983. Grizzlies, elk, eagles: wildlife diversity and the national forests. In J. Hayes, ed., Using our Natural Resources. USDA, 1983 Yearbook of Agric.: 156-165.

Salwasser, H., C.K. Hamilton, W.B. Krohn, J.F. Lipscomb and C.H. Thomas. 1983. Monitoring wildlife and fish: mandates and their implications. Frans. North Am. Wildl. and Nat. Resour. Conf. 48: 297-307

Salwasser, H., J.W. Thomas and F. Samson. 1984a. Applying the diversity concept to national forest management. Pages 59-69. In J.L. Cooley and J.H. Cooley eds., Diversity in Forest Ecosystems, Proc. of the Workshop. Univ. Georgia, Athens, Ga.

Salwasser, H., S.P. Mealey and K. Johnson. 1984b. Wildlife population viability: a question of risk. Trans. North Amer. Wildl. and Nat. Resour. Conf. 49. (in press).

Siderits, K. and R.E. Radtke, 1977. Enhancing forest wildlife habitat through diversity. Trans. North Am. Wildl. and Nat. Resour. Conf. 42: 425-433.

Thomas, J.W. 1979. Wildlife Habitats in Managed Forests: The Blue Mountains of Oregon and Washington. USDA For. Serv. Agric. Handbook No. 553. Washington, D.C. 512 p. 